\title{
EL LAICO EN LA IGLESIA ¿COLABORADOR O CORRESPONSABLE?
}

\author{
Luis Martínez Saavedra
}

El presente artículo quiere ser una respuesta medianamente fundada a diversas inquietudes que hemos ido recibiendo en el compartir cotidiano con laicos de diversas comunidades católicas dispersas en la IX Región de la Araucanía. A nuestro parecer, el núcleo central de un cierto malestar que se puede descubrir en ellos se encuentra en el aun marcado clericalismo de nuestra Iglesia católica. En efecto, si bien el Concilio Vaticano II quiso terminar con el clericalismo, en el último tiempo asistimos a un proceso de neoclericalismo que se instala por todas partes. Los laicos se sienten tratados como niños y utilizados por una institución que aman pero que se resiste a darles reales canales de participación corresponsable; se sienten bienvenidos cuando están dispuestos a hacer la voluntad del párroco, pero marginados cuando ejercen la crítica o exigen mayor participación en la toma de decisiones. Existe un gran descontento a la hora de evaluar los canales de comunión y participación pues, por lo general, los laicos son compelidos a una colaboración obediente y acrítica, en desmedro de una participación corresponsable como podria esperarse de su dignidad de hombres y mujeres adultos, discipulos y testigos, algunos de ellos por toda una vida, del Señor.

Un segundo sin sabor expuesto por los laicos tiene que ver con la pretensión, no expuesta verbalmente pero si vehiculado en actitudes y símbolos externos, del clérigo como un "super cristiano" o, en las categorias del pre-conclio, de alguien en "estado de perfección" que todo lo sabe magisterialmente por su consagración sacerdotal. El laico se siente un cristiano de segundo orden, pecador, ignorante y, por lo mismo, sin gran cosa que decir o aportar. En la misma dirección, otro sentimiento recurrente, es la sensación de muchos laicos de haber sido y ser aun hoy en dia mantenidos en la ignorancia como una forma de ejercer poder sobre ellos. No conocen la Escritura, la Historia de la Iglesia, el Derecho Canónico, etc, sino en cuanto ellos los capacita para ejercer un rol dentro de la comunidad; lo que los deja en condiciones muy precarias al momento de hacer frente a la acción autoritaria de algunos párrocos o de verse obligados a justificar alguna acción innovadora y creativa dentro de la comunidad, ya sea en la liturgia, en la tarea pastoral o en el servicio al mundo.

Por desgracia, la realidad descrita y cuestionada por muchos laicos se funda primeramente en el modo "apatronado" de ejercer la "autoridad" -en el sentido vulgar del término, es decir, como poder arbitrario- por parte de algunos ministros que debieran, al contrario, destacarse por su servicio humilde a la comunidad (cfr Mt 20,24-28). No se trata, sin embargo, en estas páginas de dar cause a una destemplada reacción anticlerical o de negar el necesario desarrollo de las instituciones eclesiales, sino de invitar a un reapropiación del dato revelado, única fuente sin norma de nuestra fe, y de la tradición eclesial que nos permitan tener una perspectiva desde la cual podamos hacernos conscientes de los relieves que existen al 
interior de nuestra larga historia como Iglesia Romana, con el fin de saber discernir en ella lo necesario de lo accesorio o lo perenne de lo anacrónico.

En esta dinámica, y aunque el Dictatus papae (1075) de Gregorio VII (10731085) afirmaba que: "la Iglesia romana no se ha equivocado ni se equivocará nunca", es necesario reconocer con humildad y enseñar, en honor a la honradez con la historia, que durante estos dos mil años hemos vivido al interior de la institución eclesial procesos claramente contrarios a las enseñanzas de las Escrituras. Uno de ellos ha sido la fuerte clericalización de la comunidad de los discípulos de Cristo que ha roto las relaciones originales de fraternidad que debian regir a los discípulos de aquel que nos mandó no llamar a nadie ni "padre" ni "maestro" ni "director", pues todos somos hermanos que compartimos una misma dignidad (cfr Mt 23,8-12). El pueblo cristiano merece conocer de ese proceso para buscar, cada vez más, ser fiel al Evangelio de Jesucristo. Por ello, nos ha parecido pertinente entregar algunas reflexiones que ayuden a esbozar un tipo de respuesta y dar luces para una búsqueda comunitaria de la Voluntad del Señor sobre algunos de esos aspectos.

En consecuencia, hemos articulado la presente reflexión a partir de cuatros grandes temas: primero, dar una mirada al "sacerdocio" de Cristo; luego, haremos un recorrido sobre el dicho proceso de clericalización que vivió el cristianismo católico en estos dos mil años; en seguida, presentamos algunas reflexiones sobre la ministerialidad como nota característica de la Comunidad Cristiana en su conjunto. $Y$, finalmente, luego de un pequeño interludio medieval en torno a la experiencia eclesial de Francisco de Asis, damos algunas pistas para la superación de los impasses actuales, sobre todo, de aquellos que hacen referencia a cierto estilo de ejercer los ministerios ordenados y a las mutuas relaciones entre los miembros de la Iglesia.

\section{A. El sacerdocio de Cristo}

Jesús, si se nos permite el anacronismo, fue un laico, itinerante y marginal; sin formación ni rabínica ni sacerdotal se acerca más a la imagen de un profeta carismático. Su conciencia mesiánica apuntó siempre a la realización del proyecto de Dios para todos los hombres, cuya mediación no es otra que la asunción de la solidaridad con los que sufren (Mt 25,31ss) ${ }^{1}$ por lo cual no se identificó ni con el sacerdocio ni con el poder de los escribas. De hecho, el título que Jesús se otorga a sí mismo en los evangelios no es otro que ser un Hijo de hombre, es decir, un hombre como todos, siendo los textos más tardíos del Nuevo Testamento quienes desarrollarán una cristología tanto en categorias sacerdotales como sacrificiales.

En efecto, las 15 referencias a Jesús como Sumo Sacerdote que aparecen en el Nuevo Testamento se encuentran todas ellas en la Carta a los Hebreos $(2,17$; $4,14 ; 4,15 ; 5,6 ; 5,10 ; 7,3 ; 7,15 ; 7,17 ; 7,21 ; 7,26 ; 8,1 ; 8,4 ; 8,6 ; 9,11 ; 10,21)$, que contrariamente a la interpretación que tradicional que se le ha dado, es una declaración del término de todo tipo de mediación sacerdotal y sacrificial, pues en Jesús todos los hombres hemos experimentado la amistad de Dios. El autor de la carta a los hebreos invita, por una parte y en controversia con los sectores judeocristianos 
de las primeras comunidades, a dejar de lado las prácticas en torno al Templo ya que en Jesús quedó claro que éstas están obsoletas; y por otra parte, hace una presentación de la salvación traída por Jesús, ocupando las categorías religiosas que para ellos resultaban más comprensibles, pero cooptándolas en favor del "único" sacerdocio de Cristo que nada tiene que ver con una casta sacerdotal como la del sacerdocio de Aarón o del sacerdocio levítico, ambos ligados a la segregación cultual $(5,11-6,10)$. El sacrificio de Cristo no consistió en ritos sino en la entrega de su propia vida por amor a Dios y el bien de sus hermanos y cuyo el efecto es perenne, por lo que ya no se requiere reiterar los sacrificios en un templo. De hecho, para los discípulos de Jesús, el único Templo es la misma humanidad resucitada de Cristo (cap. 8-9, 10,1-18).

En cuanto a una lectura sacrificial de la vida de Jesús y, fundamentalmente, de su muerte en cruz sucede algo parecido. Veamos, por ejemplo, su denominación como Cordero de Dios. El título como tal pertenece a la tradición joánica desarrollada en el libro del Apocalipsis (Jn 1,29. 36; Ap 5,6. 8. 13; 6,1. 12.16; 7,9. 10. 14. 17; $12,11 ; 13,8 ; 14,1$. 4. 10; 15,3; 17,14; 19,7. 9; 21.9. 14. 23-13. $27 ; 22,1)$. Claramente la intención de esta denominación de Jesús es poner toda su acción en un trasfondo pascual (Jn 18,28; 19,36; Mc 14,24; Lc 22,20; Mt 26,26ss; 1Cor 5,7;10,23-27; $1 \mathrm{Pe} \mathrm{1,19;} \mathrm{Heb} \mathrm{11,28),} \mathrm{que} \mathrm{permita} \mathrm{su} \mathrm{comprensión} \mathrm{desde} \mathrm{la} \mathrm{perspectiva} \mathrm{del} \mathrm{Éxodo}$ y la Alianza. Es decir, que aquel que se identifica por la manducación con este cordero lo hace en cuanto se dispone a iniciar un nuevo éxodo, una salida de las estructuras de muerte y opresión en que se encuentra para llegar a tierras de vida plena y de liberación definitiva. Este es, por lo demás el sentido último de comulgar con el cuerpo y la sangre de Jesús. Quién come de ese pan y bebe de esa copa pero no realiza este "paso", come su propia condenación.

En realidad, la conciencia de las primeras comunidades reconoció rápidamente que la entrega radical de Jesús al cumplimiento de la Voluntad de su Padre podía ser comprendida en categorias sacrificiales, pero guardando siempre la distancia tanto con los sacrificios paganos como judios que buscaban por la manipulación mágica obtener el favor de Dios. Claramente el sacrificio de Jesús se les mostraba ante sus ojos como de otro talante, muy lejano a los sacrificios rituales de los sacerdotes, pues era una entrega existencial, es decir, de su vida entera entregada cotidianamente por la vida de sus hermanos, o en las categorías de Jesús, por el Reino de Dios anunciado y hecho realidad como buena noticia para los pobres (Jn $6,51)$.

Por lo mismo, la primera reacción de los discípulos, luego de su partida, no fue organizar una casta sacerdotal o una minuta de ritos sacrificiales en torno a un templo, sino que se reunieron en torno a una red de comunidades fraternas y solidarias que hacian ellas mismas presentes ese Reino anunciado y querido por Jesús (Hch 2, 42-47; 4,32-35); organizaron el servicio a los pobres (Hch 6, 1-7) y hacian memoria de Jesús a través de signos muy sencillos como bautizar, partir el pan, ungir enfermos, etc. que nada o poco tenian que ver con las prácticas rituales de sus contemporáneos. Los discípulos mismos, hombres y mujeres, no son, primeramente, los precursores de los obispos actuales en cuanto a una jerarquia $u$ orden sacerdotal bien estructurados, sino testigos del Resucitado convencidos de la fuerza de su mensaje y de su praxis liberadora.

Los primeros ministerios nacieron en respuesta a las necesidades de la comu- 
nidad: presbiteros (ancianos) que presidan las comunidades y ayuden a transmitir y conservar la memoria de Jesús, diáconos (servidores) que se dediquen a la atención de los necesitados, obispos (vigilantes) que ayuden a mantenerse atentos a las nuevas necesidades que las comunidades deben enfrentar, apóstoles, profetas y doctores itinerantes y carismáticos que enseñen y animen a las comunidades en el seguimiento de Cristo, etc. Todos ellos buscan testimoniar al Mesías servidor de los pobres y sufrientes a través de gestos y palabras comprometidos con la vida y la justicia.

Curiosamente, sin embargo, y como veremos más adelante, con el paso paulatino del tiempo esta red de comunidades de pobres y para los pobres que surgió de la predicación de Jesús y que se fue organizando con gran dinamismo y con igual sencillez en las riveras del mar Mediterráneo, se vió transformada, poco a poco, y por la influencia del Imperio Romano, en una nueva "religión" cargada de ritos, de cánones, de templos, de una organización jerárquica apoyada fuertemente en la "sacerdotalización" de sus ministros. Las reflexiones de San Agustín (bautizado el 387-430) y de Dionisio Areopagita (s V-VI) sobre el "carácter" impreso por el orden y las exigencias del "celibato", terminarán por apartará los ministros de la vida cotidiana de las comunidades, especialmente, del trabajo y la familia. En el caso de los presbíteros, esta última prescripción disciplinar se impondrá a partir del II Sínodo de Letrán en el año 1139, pero sólo se hará efectiva en la Iglesia de Occidente como fruto del nacimiento de los seminarios creados con el concilio de Trento ${ }^{2}$.

En la raiz de este proceso se encuentra la acentuación excesiva y bastante alejada del sentido bíblico neotestamentario de Jesús como Sumo Sacerdote que terminó por llevar a la sacerdotalización tanto del mismo Jesús como de toda la vida cristiana. La obra de Anselmo de Canterbury (1033-1109) Cur Deus homo, buscando responder a la pregunta del por qué Dios se hizo hombre, se apoyará principalmente en los textos que hablan de Jesús como Sacerdote-Mediador y de su entrega sacrificial. Su interpretación exclusivamente sacrificial de la vida de Jesús se impondrá y marcará profundamente la comprensión creyente de Jesús hasta nuestra época como mediador sacrificante y sacrificado. De hecho, para San Anselmo, la razón de la encarnación no es otra que satisfacer a Dios por una culpa contraída en el pecado de Adán; en otras palabras, los hombres han pecado ofendiendo a Dios y son incapaces de satisfacer por su acción, por lo que se hace necesario constituir un salvador que "satisfaga adecuadamente» en nombre de la humanidad al Dios afrentado, e impida que su creación se pierda definitivamente o fracase su designio eterno. Ahora bien, como los hombres, por su pequeñez, son incapaces de ofrecer un sacrificio que pueda satisfacer plenamente a Dios, se realiza la encarnación que apunta exclusivamente a la eliminación o perdón de los pecados a través del sacrificio en la cruz de un Sumo Sacerdote, al mismo tiempo hombre y Dios.

Por supuesto, en esta lectura quedan al margen aspectos fundamentalmente positivos de la cristología bíblica, como son: la unidad y consecuencia entre la vida de Jesús y su muerte, la centralidad de su predicación del Reino de Dios, la gratui-

2 Cfr R. GRYSON, "Dix ans de recherches sur les origines du célibat ecclésiastique" en: RTL 2 (1980) 157-185. 
dad de la autocomunicación de Dios para hacernos hijos en el Hijo, la teología de la divinización del hombre por la humanización de Dios y la acción del Espíritu Santo, la kenosis del Verbo, etc. El mismo rostro amoroso del Padre y su proyecto de vida para sus hijos, queda oculto tras una cortina sacrificial muy difícil de comprender, al menos, por los que somos padres como él, salvando la diferencia por supuesto (cfr Mt 7, 11).

\section{B. Hacia una Iglesia de clérigos y laicos}

Practicamente hasta el siglo V, la comunidad cristiana mantuvo un modelo de organización marcado por una estructura sinagogal de carácter laical y diaconal. Ellas se autocomprendian como una asamblea convocada por Dios, profundamente misionera y enraizada en las capas marginales del Imperio. Tienen conciencia de la igualdad fundamental de todos sus miembros como discipulos y hermanos del Señor, y acogen con gozo la multiplicidad de carismas y ministerios que les prodiga el Espíritu. Avanzada la época patrística y junto con ella la mayor institucionalización de la comunidad, se comienza a distinguir entre laicos y clero, pero sin que ello implicara una superioridad de los últimos sobre los primeros sino conservando la igualdad bautismal ${ }^{3}$.

Durante practicamente todo el primer milenio, los laicos siempre fueron considerados corresponsables con el clero en sus esfuerzos por el establecimiento del Reino de Dios y se les reconocía como "portadores del Espíritu Santo" o de estar "conducidos por el Espíritu Santo". En consecuencia, los laicos actuaban como verdaderos miembros corresponsables en la marcha de la Iglesia y participan activamente en la vida de las comunidades: elegian sus pastores -incluso algunos de ellos fueron elegidos obispos o papas ${ }^{4}$, convocaban y participaban en los concilios, y podian aprobar o desaprobar ciertos actos y decisiones de la Iglesia. El derecho a elegir a los propios pastores se mantuvo como una norma comúnmente aceptada hasta Gregorio IX (1227-1241) quien declaró inválidas las elecciones realizadas con participación de los laicos. Sin embargo, ello obedeció a la necesidad de independizarse del poder de aquellos nobles y potentados que interferian mañosamente en las elecciones, pero sin excluir a los laicos de fe probada que mantendrán un rol activo en ellas ${ }^{5}$.

Los estudios actuales llaman la atención, por ejemplo, sobre la categoria de la recepción. Ella fue una práctica constante en las comunidades del Patriarcado de Roma durante el primer milenio -el principio rige hasta hoy en las Iglesias de Oriente- y correspondia a un proceso activo y de asimilación vital que hace el pueblo cristiano de verdades y normas emanadas del magisterio, es decir, un proceso dinámico de ejercicio de la corresponsabilidad por parte de todo el pueblo -es el sensus Cfr E. HORNAERT, La memoria del Pueblo cristiano, Madrid, 1986.

4 Es el caso de los papas Benedicto VIII (1012-1024) y Juan XIX (1024-1032). Como hecho anecdótico, recordemos que san Ambrosio de Milán fue elegido obispo sin estar siquiera bautizado. 
fidelium puesto en práctica ${ }^{6}$. No se trata, entonces, de una simple obediencia ciega sino del ejercicio de un derecho del Pueblo de Dios de interactuar corresponsablemente en la vida de la comunidad, sobre todo en lo que corresponde a mantener la correcta memoria de Jesús y a las exigencias de ortopraxis que de ello se desprende. En el ejercicio de la recepción la comunidad hace suyo o no un dato eclesial, una normativa concreta, una práctica litúrgica, etc.

Adentrándonos en el segundo milenio, al mismo tiempo que se avanzaba en la controversia con las Iglesias Orientales, la Iglesia Romana se distanciaba y olvidaba, cada vez más, la rica perspectiva bíblica y patrística del primer milenio en provecho de la consolidación de una Iglesia imperial. La reforma impulsada por Gregorio VII a través de su Dictatus papae, junto con acentuar fuertemente la organización de la Iglesia como una monarquía sacerdotal, buscará, a su vez, poner fin a la participación de los laicos en la elección de los obispos y presbiteros, lo que, según se dijo, sólo se impondrá casi dos siglos después. Con esta misma reforma, el antiguo monje de Cluny, comienza también una reforma litúrgica centralizada y marcada por las prácticas monacales que tendrán por efecto la exclusión paulatina de los laicos, contrariando las prácticas del primer milenio en donde hubo una gran variedad de liturgias que reflejaba la creatividad e inculturación de la fe en cada Iglesia local'.

En efecto, en los primeros siglos de la Iglesia la liturgia era vivida como una verdadera celebración de toda la comunidad, en donde los «laicos» participan activamente en una verdadera asamblea fraterna de los discípulos de Jesús. Esto se perderá con las reformas de Gregorio VII y, posteriormente, de Bonifacio VIII (12941303) que introducen una "clericalización" ${ }^{8}$ de la liturgia que reduce a una gran pasividad al pueblo que, por otra parte, debido al uso de una lengua como el Latín que había dejado de ser la lengua del pueblo desde hacía varios siglos, cada vez comprende menos los gestos y las palabras que obedecen a estratos culturales de una reducida elite. Como se podía esperar, la participación laical en la liturgia se redujo a prácticas devocionales que poco o nada tenian que ver con la celebración de la liturgia oficial reservada al clero y a los monjes.

Más tarde, Pio V (1566-1572), dentro de la dinámica de la Contrarreforma, impone de forma rígida una comprensión de la liturgia basado en el rubricismo, en vista a la creación de una liturgia única para todas las iglesias bajo el Pontificado romano. Evidentemente la imposición de una liturgia única redujo la espontaneidad de las celebraciones y limitó la participación activa de la comunidad, pues el clero se "profesionalizó" conviéndose en el actor principal de una liturgia extraña a la

6

Para Y. CONGAR, la recepción es «el proceso por el que el cuerpo eclesial hace verdaderamente suya una determinación que él no se ha dado ha si mismo, reconociendo en la medida promulgada una regla que conviene a su vida" ("La recepción como realidad eclesiológica», en Concilium 77(1972)57-85, aqui p.58).

Es el caso de los papas Benedicto VIII (1012-1024) y Juan XIX (1024-1032). Como hecho anecdótico, recordemos que san Ambrosio de Milán fue elegido obispo sin estar siquiera bautizado. 
vivencia de la comunidad local. Se pasa así de una unidad pluriforme a una homogeneidad uniforme, que deja sólo cabida, y con restricciones, a los ritos orientales que permanecen unidos a Roma. Sólo a partir de 1903, con Pío X, los laicos comienzan a recuperar una participación más activa en la celebración de los sacramentos «recitando» algunas partes de la misa como el gloria y el credo.

Todo este proceso se verá reforzado por la lectura eclesiocéntrica que se hará de la salvación bajo el pontificado del papa de Bonifacio VIII quien, en su bula Unam Sanctam (1302) declarará cerradas las posibilidades de salvación a todos aquellos que no adhieran durante su vida a la Iglesia Romana -doctrina que será posteriormente refrendada por los concilios de Florencia y Trento $^{9}$ - Se consolida asi el paradigma sagrado-profano que dará sustento al binomio clérigo-laico, acentuando la distinción jerárquica y ontológica entre ambos, con el consecuente quiebre, sino teórico al menos en la práctica, de la igual dignidad bautismal en que se sustentaba la fraternidad original de los discípulos de Jesús.

Esta concepción influyó en la eclesiología acentuando la distinción entre clero dispensador de la gracia santificante a través de los sacramentos, y pueblo receptor pasivo de ella. La distancia entre unos y otros se fue haciendo cada vez mayor, hasta hacer de los primeros los protagonistas de la vida eclesial, son ellos los que enseñan, los que dirigen y santifican; los segundos, escuchan, obedecen y se acercan a los sacramentos como fieles. La dimensión de fraternidad, de discipulado compartido, de corresponsabilidad, se distorsionan y transforman a la comunidad de hermanos en una "sociedad jerárquicamente organizada». La eclesiologia pasó a ser una verdadera "jerarquilogía"10. Los "presbiteros" se transformarón en "ministros sagrados", en "sacerdotes", al extremo de hacer de ellos un "ordo" contrapuesto al resto de los cristianos que pasarán a formar la "plebe".

Como resultado obvio de este proceso, el laico pasó de ser corresponsable a ser, en el mejor de los casos, un colaborador o un sujeto pasivo. Se le ve, cada vez más, como un "fiel" que se encuentra en un estado de menor perfección debido a su incapacidad de resistir a la "concupiscencia de la carne" y a su cercanía con los asuntos del "mundo", entendido éste como profano y como espacio del demonio de allí y al contrario la comprensión de la Vida Religiosa como fuga mundi. Los laicos, excepción hecha de los nobles que conservarán un grado bastante importante de ingerencia en las cuestiones eclesiales, serán vistos como incapaces de pensar, de enseñar y de participar en los asuntos eclesiales. En el transcurso del segundo milenio el laico se transforma, poco a poco, en "hijo", "lego", "iletrado" e "idiota"11. Y. Congar recoge frases muy duras al respecto, como esta de dom Guéranger: "La masa del pueblo cristiano es esencialmente gobernada y radicalmente incapaz de ejercer ninguna autoridad espiritual, ni directamente, ni por delegación"; o esta otra del papa Pío X: "En cuanto a la multitud, no tiene más derecho

Para una mejor comprensión Cfr Y. CONGAR, "L' Eglise, Sacrement Universel du Salut" en: VVAA, L'Eglise aujourd'hui, Paris, 1967.

Y. CONGAR, Jalones para una teologia del laicado, Barcelona, 1963, p.62.

Cfr Y. CONGAR, Jalones para una teologia del laicado, Op.cit., 285ss; J. ESTRADA, La identidad de los laicos, Op.cit., 292ss. 
que el de dejarse conducir y, como dócil rebaño, seguir a sus pastores". Se ha producido entonces el quiebre de un paradigma eclesial basado en la circularidad fraterna y carismática, para pasar a un modelo de Iglesia basado en la "paternidad" y superioridad de unos, los menos, sobre la gran masa de los llamados "fieles".

Otro elemento central en este proceso de clericalización de la estructura eclesial y de su consecuente puesta al margen de los laicos, fue el olvido de la Sagrada Escritura como referencia constante para la praxis de la Comunidad Cristiana. Cuando en el año 1550, luego del quiebre definitivo de la cristiandad medieval y en un esfuerzo de contra-reforma, fue elegido el Papa Julio II, los cardenales le hicieron llegar algunos consejos para la buena marcha de su pontificado. Uno que resulta, al menos, sorprendente, es la exhortación que le hacen de prohibir la lectura de la Sagrada Escritura al pueblo cristiano por el miedo a que ello los llevara a darse cuenta de la distancia que hay entre el Evangelio y la práctica eclesial y, por lo mismo, a rebelarse frente a su autoridad:

"La lectura del Evangelio no debe permitirse sino lo menos posible, sobretodo en lengua moderna y en los países sometidos a vuestra autoridad. Lo poco que se lee generalmente en la misa debería bastar, y sería preciso prohibir que se leyera más. Mientras el pueblo se contente de ese poco, vuestros intereses prosperarán, pero, desde el instante que querrán leer más, ellos comenzarán a sufrir. He aqui el libro que, más que ningún otro, provocará rebeliones contra nosotros, tormentas que nos pueden perder. En efecto, cualquiera que examine diligentemente la enseñanza de la Biblia y la compare a lo que pasa en nuestras Iglesias encontrará rápidamente las contradicciones, y verá que nuestras enseñanzas se apartan habitualmente de la de la Biblia y lo más frecuente es que se opongan a ella. Si el pueblo se da cuenta de ello, nos provocará hasta que se le revele todo, $y$ entonces nos convertiremos en objeto de las risas y del odio universal. Es necesario entonces que la Biblia sea retirada y sustraida con celo de las manos del pueblo, pero sin provocar tumulto."'2

En el mismo sentido y, en un intento por controlar la ya irreversible Reforma Protestante que buscaba fundarse en la "sola Escritura", y que, por lo mismo, hacía grandes esfuerzos por traducir y llevar a todos los hogares el texto sagrado, la Iglesia católica pondrá las traducciones de la Biblia en el Index (lista de libros prohibidos para la lectura de los cristianos) y recomendará el uso sólo de la traducción Vulgata (traducción latina de San Jerónimo). De este modo, los laicos verán como el texto que debía orientar toda la praxis eclesial quedaba confiscado en las manos del clero, único capaz de leer el latin, debiéndo contentarse con las explicaciones dadas en los "sermones" que vienen a reemplazar las antiguas "homilias" o conversaciones en donde la comunidad acogia el texto leído y reflexionaba sobre su vida y la vida de la comunidad a partir de él. Así, en base al Catecismo de Trento, concebido como un subsidio para los párrocos en su tarea de enseñar al Pueblo y frenar así el avance de la Reforma, los sermones fueron, poco a poco, privando al Pueblo de la Biblia. 


\section{UnA IGLESIA TODA ELLA MINISTERIAL}

Sólo en la segunda mitad del siglo XX, el Concilio Vaticano II marcará el quiebre de ese modelo eclesial jerarcológico para recuperar un modelo más original y mistérico. El Concilio fue sentido por muchos como una gran manifestación del Espíritu Santo, como un «nuevo pentecostés" en donde la Iglesia católica, reunida para revisar y criticar en profundidad su pasado a la luz del Evangelio y de los nuevos «signos de los tiempos», comenzó un proceso de vuelta a los orígenes marcado por un nuevo paradigma eclesial de la Iglesia como "Pueblo de Dios" ${ }^{13}$. Con la inversión de los capítulos sobre la jerarquía y el pueblo de Dios, el Concilio imprimió a la eclesiología una verdadera «revolución copernicana» que, al recuperar esta comprensión más bíblica de la Iglesia, permitirá en los años posteriores el desarrollo de una práctica eclesial que ha ido potenciando, poco a poco, la participación activa y corresponsable del laicado.

En lo que respecta al clericalismo, el Concilio quiso, de hecho, desacerdotalizándo el vocabulario en torno a los ministros ordenados devolver a la comunidad cristiana su igualdad original: en el Nuevo Testamento se habla siempre de "discípulos", de "elegidos" o de "santos", resaltándose la igual dignidad de los hermanos de Jesús. El decreto Presbyterorum ordinis muestra claramente esta intención ${ }^{14}$ al designarlos como "presbiteros" y referirse a su función sacerdotal como un ministerio o servicio al interior de la comunidad cristiana toda ella sacerdotal. Para el Concilio Vaticano II no se puede comprender correctamente los ministerios ordenados sin considerar previamente el sacerdocio común de los fieles (PO 2). Es decir, que los ministros deben situar su ministerio sacerdotal al interior de una comunidad sacerdotal y, por lo mismo, no erigirse como una casta separada de la común condición eclesial de los bautizados. Ellos no son el "centro" de la vida eclesial, sino servidores de la misma ${ }^{15}$.

A partir de la recuperación del sacerdocio común de los bautizados, la ministerialidad se recupera como una nota fundamental de toda la comunidad, pues, toda ella se entiende al servicio y en relación con algo mayor: el Reino de Dios. Por lo mismo, todos los ministros y los ministerios particulares deben estar en sintonía con dicha ministerialidad radical. La ministerialidad en la Iglesia apunta al anuncio de Jesús, por lo tanto, sus ministros, sus ritos y sus doctrinas deben estar en sintonía con aquello que se quiere anunciar. Toda la Iglesia debe ser mediación para el

«Se ha dicho que, al invertir el capítulo, inicialmente previsto como tercero, para ponerlo como segundo, es decir, al tratar primero del conjunto de la Iglesia como Pueblo de Dios y a continuación de la jerarquía como servicio a este Pueblo, hemos hecho una revolución copernicana. Creo que es verdad: esta inversión nos impone como una especie de constante revolución mental, cuyas consecuencias no hemos terminado aún de medir. Pero hay que reconocer, que la inversión del orden de los capitulos no ha hecho valer todas sus implicaciones en el capitulo tercero, consagrado a la jerarquia" (Card. L. SUENENS, "Quelques tâches théologiques de I'heure», en: Concilium, Supplément au n.60 (1970) 33).

Resulta muy interesante ver la evolución del título del documento en la medida que se avanzaba hacia su redacción final. Hubieron siete redacciones: De clericis (abril 1963), De sacerdotibus (octubre 1964), De vita et ministerio sacerdotalis (noviembre 1964, mayo 1965 y noviembre 1965) y, finalmente, Presbyterum ordinis (mayo 1965 y noviembre 1965).

Cfr S. DUFOUR- R. PARENT, I ministeri, Brescia, 1995, pp. 65-82. 
encuentro del hombre con Jesús y con su Reino, sin miedo a que se nos llene la Iglesia de "pecadores y extranjeros". Si se quiere ser fiel a esta nota distintiva de la comunidad de los discípulos de Jesús, la expresión ministerial debería emprender un camino de revitalización a partir de la trilogía "Reino de Dios"/ "comunidad ministerial"/ "mundo contemporáneo", superando el binomio Clérigos-Laicos que responde al binomio Iglesia-Mundo como entidades separadas en la línea de la oposición sagrado-profano, lo que resulta contrario al cristianismo.

La ministerialidad radical de la Comunidad Cristiana nos hace avanzar hacia una comprensión eclesial que le impide a la misma Iglesia erigirse como centro de la historia de salvación y en punto de referencia único para el encuentro con Dios. Si esto sucediera, el resultado sería la incomunicación de la comunidad con el mundo que debe servir y, en particular, con las otras religiones y confesiones cristianas, en las cuales no podemos negar la presencia viva, permanente y salvífica del único Espíritu de Cristo (cfr RM 28). En este sentido, en el servicio y en el reconocimiento de la presencia del Reino más allá de sus fronteras (cfr RM 15. 18) y aun antes de la llegada del misionero, la Iglesia se salva de convertirse en una secta. Por lo mismo, la comunidad debe estar atenta a no apropiarse de aquello que está llamada a anunciar y a hacer realidad a través de su ministerialidad, el Reino de Dios. La base de la ministerialidad de la comunidad debe estar entonces fuertemente unida con el servicio al Reino y al sacerdocio común de todos los bautizados. Estos son el punto de referencia y de validación de toda la expresión ministerial de la Iglesia y de sus ministros, pues, la ministerialidad eclesial debe ser verdadero "sacramento" de aquello que se quiere anunciar.

Ahora bien, tal ministerialidad eclesial pasa a través de una gran gama de expresiones ministeriales, unas estables y otras temporales, locales o itinerantes, ordenadas o laicales, más institucionales o más carismáticas, etc. Se trata, entonces, de no reducir la ministerialidad eclesial a su sola expresión sacerdotal, de lo contrario, corremos el riesgo de reducir la ministerialidad de la Iglesia al ejercicio de la función sacerdotal en manos de una "casta", introduciendo una discriminación inadecuada entre cristianos de primera y segunda clase, en contra de la igualdad fundamental de los discípulos de Cristo por el bautismo.

Los ministerios y, por lo mismo, los ministros deben responder, tanto en su interioridad como en su proyección externa, a la experiencia y las necesidades de esas comunidades todas ellas ministeriales. Los ministros no son "profesionales" sino enviados de la comunidad que da y quita los ministerios según los tiempos y las necesidades de la misión. Aquí, se hace necesario conciliar dos principios ministeriales, a saber: el ministro como mandatado de una comunidad y el ministro como alguien carismático, es decir, alguien que recibe del mismo Espíritu un carisma para el servicio de la comunidad. Al respecto es interesante recordar que durante los dos primeros siglos de la Iglesia, el gesto sacramental de la imposición de las manos buscaba constatar la presencia del Espíritu en el nuevo ministro más que querer comunicarlo. Es decir, la comunidad discernia un don que el Espíritu le regalaba para una mejor realización de su misión ${ }^{16}$.

16

Cfr A. FAIVRE, Naissance d'une hiérarchie. Les premieres étapes du cursus clérical, Paris, 1977, p. 54. 
En efecto, todo ministerio debe referirse constantemente al testimonio que nos dan las Escrituras sobre el Espíritu animando a las comunidades y confiriendo a los distintos miembros dones especiales o carismas, ya sea transitorios o permanentes, para el servicio y edificación de la misma comunidad cristiana, y como servicio a la realización definitiva del Reino anunciado por Jesús. Dichos ministerios son dados para el bien de las comunidades y destinados a la práctica del amor fraternal que proyecta la comunidad hacia el compromiso con el Proyecto de Dios. Los ministerios no deben entenderse como una promoción en la escala jerárquica o como acceso al "poder", sino como servicio a la comunidad $\mathrm{y}$ al mundo.

En el Nuevo Testamento, como hemos visto, si bien nos encontramos con una cierta distinción y jerarquía de oficios o carismas dentro de la naciente Iglesia de Cristo (obispos, presbíteros, diáconos, apóstoles, profetas, doctores, etc.), no aparece la fundación de una gran institución eclesiástica, centralizada e inmutable en sus ministerios y en sus estructuras; éstas son fruto de las respuestas que las comunidades fueron dando a través de su historia, a determinados problemas o desafíos que debieron enfrentar y, en consecuencia, las comunidades están llamadas a discernir, en la actualidad y de cara al próximo siglo, sobre su pertinencia o anacronismo. Afirmar que una determinada configuración epocal sea de obligación para todas los tiempos y universos culturales en donde las comunidades sean llamadas a testimoniar con el correr de la historia, sería casi una ofensa al dinamismo del Espíritu que "sopla donde él quiere".

Si la actual configuración, sobre todo de los ministerios ordenados o más institucionales, responde a ciertos parámetros culturales de un momento dado de la historia y en un universo cultural determinado, la cuestión que surge es saber si esas opciones son absolutas para toda encarnación del cristianismo o son relativas a una particular encarnación histórica del mismo. En concreto, ¿podemos asegurar que dichas categorias posean estatuto de norma o canon para todas las encarnaciones posteriores del cristianismo? Desde nuestra perspectiva creemos que no todas. En este sentido, un gran desafío para el próximo siglo será, entonces, avanzar hacia una necesaria "autoctonización" de los ministerios que permita a la actual disciplina acoger nuevas concreciones ministeriales de acuerdo a la realidad cultural de nuestras comunidades y que al mismo tiempo genere una cada vez mayor participación laical en vista al ejercicio de su sacerdocio bautismal.

Claramente, tanto los ministerios como el acceso a ellos ha evolucionado con el tiempo y de acuerdo a las necesidades que la misión iba planteando en los diversos mundos que los discípulos se hacian presentes. Recordemos, por ejemplo, que el sacerdocio lo ejercieron hombre casados hasta bien avanzado el segundo milenio -sin olvidar que dicha práctica es la actual en muchas Iglesias hermanas-, lo mismo ocurre con la elección de obispos y párrocos, con la diaconía femenina, etc. Por la concepción de los ministerios desde la comunión y el servicio, estos permanecieron durante largo tiempo abiertos a hombres y mujeres, sin que existiera, por lo demás, la poco feliz distinción entre "laicos" y "clérigos".

Una de las cuestiones que las comunidades del próximo siglo deberán enfrentar será abrir, al menos, un debate en torno a la "Pastoral Vocacional" que 
insiste en un solo modelo de ministerio sacerdotal basado en el celibato, sin tener en cuenta la tradición de siglos en nuestra propia Iglesia y en las Iglesias hermanas del sacerdocio de los "hombres probados en su fe", sean estos casado o célibes; y otra sería, pero el debate está cerrado, tomar en serio la cuestión de la participación ministerial de las mujeres: ellas, tanto como los hombres, son capax dei y han mostrado a través de los siglos su indiscutible entrega misionera y ministerial. La consagración de diaconisas estuvo presente en la Iglesia occidental hasta el s. IV y hasta el s.XI en oriente, ellas tomaban la palabra en la asamblea y aconsejaban a los obispos en su labor pastoral. También en muchas comunidades se da testimonio del ministerio ejercido por viudas y vírgenes consagradas $^{17}$

Sin embargo, en la actualidad, si bien se reconoce a las mujeres algunos ministerios particulares, el camino a los ministerios más institucionales, consagrados y canónicos está cerrado para ellas. La expresión ministerial en la Iglesia no ha sido capaz de reconciliarse con lo femenino como normal en la Iglesia y no como un peligro para la ministerialidad. Todas las instancias de decisión pastoral excluyen sistemáticamente la participación femenina privándose a la comunidad tanto del aporte como de la sensibilidad propios de la mujer. Se hace urgente superar todo forma de clericalismo y de machismo al interior de las comunidades, pasando de un modelo ministerial comprendido como poder a otro de servicio que acentúe con mayor fuerza la igualdad fundamental de todos los bautizados en el seguimiento de Cristo y que, de una vez por toda, deje de considerar a los laicos, hombres y mujeres, como púberes incapaces de ejercer la corresponsabilidad en todos los niveles de la Iglesia.

La separación de la fe y la vida nos ha llevado a un tipo de ministerios que no responden a su sentido último de servicio al mundo, están estructurados sin tener en cuenta las necesidades de los hombres y mujeres de hoy, en un lenguaje y una disciplina que no corresponde al lenguaje y la cultura contemporánea, o si lo hace, es sólo en referencia a un solo universo cultural -europeo- sin acoger la pluralidad de las culturas que conviven en el mundo. No hay ministerios adecuados para el mundo indígena, ni popular, ni juvenil, etc.

Lamentablemente, aunque el Concilio Vaticano II apuntó claramente hacia allá, aun la riqueza de la pluriformidad de la ministerialidad eclesial no logra desarrollarse. En la actualidad y en la práctica el modelo del ministro "sacerdote" y mediador actuando "in persona Christi" que se impuso a partir del segundo milenio no ha logrado ser superado. Antes bien, en el último tiempo se ha reforzado. Los ministerio Ilamados "laicales", por ejemplo, aparecen aún como sucedáneos o de segunda calidad y los laicos, como tales, continúan siendo vistos como miembros pasivos de una institución eclesiástica que sólo en ciertas circunstancias excepcionales los autoriza o, mejor dicho, les concede debido a la falta de sacerdotes, colaborar en el ejercicio de uno u otro ministerio. Es decir, en la práctica una desvinculación y olvido del sacerdocio común de la comunidad. Aparece asi, una suerte de escala ordenada de arriba hacia abajo, en donde el lugar más alto está ocupado por los ministerios ordenados enten- 
diendo los demás sólo como suplencia necesaria en aquello que, por el momento, los obispos, sacerdotes y diáconos no logran realizar, o como estadios previos en el camino al sacerdocio o sólo como ayuda para el buen ejercicio de los ministerios ordenados ${ }^{18}$.

\section{Interludio medieval: la experiencia eclesial de Francisco de Asís}

Antes de pasar a nuestra última parte que quiere avanzar algunas pistas para una mejor realización de la corresponsabilidad laical en la Iglesia, hemos querido traer a la memoria la experiencia eclesial de Francisco de Asis (11821226) pues ella, aunque se desarrolló en la época de los papas Inocencio III (1198-1216) y Honorio III (1216-1227) que llevaron al Pontificado Romano a su máximo esplendor imperial y sacerdotal, quiso recuperar una expresión más evangélica de la Iglesia como fraternidad de hermanos iguales, fundamentalmente laicos y al servicio de los pobres. La fraternidad eclesial que Francisco propone se encuentra dentro de la mejor tradición de la Iglesia de comunión vivida durante el primer milenio que bien podría ser hoy para nosotros un modelo y una referencia para la vivencia de una Iglesia más fraterna y participativa.

Resulta sintomático de lo anterior que la palabra más usada por Francisco en sus escritos sea "hermano" que aparece 242 veces. De hecho, Francisco no fundó una "orden" sino una "fraternidad", cuyos límites se confunden con el mundo, es el Hermano de todos los hombres y del cosmos entero. De alli, por ejemplo, su negativa a instalarse en un "convento" que pudiera cercar su fraternidad, pues, para él el mundo entero es el convento.

Francisco entiende su llamado a la vida en fraternidad, como un llamado a la fraternidad universal, abierta a todos "amigo o enemigo, ladrón y salteador", según la expresión de la Regla no Bulada VII, $15^{19}$. Para él la fraternidad no se entiende como algo institucional sino como fruto del amor espiritual que hace a los hermanos verdaderas madres en el cuidado solícito del otro (cf $1 R$ IX,14; $2 R$ $V I, 10)$. En este sentido, la fraternidad franciscana es una fraternidad de "hermanos menores", es decir, una fraternidad de servicio, que vive el mandato evangélico de "lavarse los pies unos a otros" (1R VI, 3), pues todos se tienen por los menores de entre todos los hombres (cf Adm XII ). La fraternidad de hermanos menores evoca la igualdad fontal de la misma Trinidad, alli nadie es mayor o menor, o está antes o después, sino que la diversidad se unifica en el amor del uno por el otro y en el amor de todos por el hombre, creado a su imagen y semejanza, y por la creación entera.

Algo de eso se puede traslucir en la última Instrucción sobre algunas cuestiones relativas a la colaboración de los fieles laicos en el ministerio de los sacerdotes, que reedita una perspectiva clericalista, basada en el derecho canónico que no recoge ni la teología ni la rica experiencia del post-Vaticano II (cfr B. SESBOUÉ, No tengan miedo, Santander, 1998, pp. 177ss ). 
En su Testamento, Francisco confiesa como su conversión es fruto del encuentro con los leprosos en quienes se le manifiesta la Voluntad de Dios de dejar el "mundo" (cf Tes 1-4), instalándose a su lado y desposando a "Dama Pobreza". El Hijo de Pedro Bernardone, comerciante exitoso de la burguesía emergente de Asís, se convierte así, por esta opción radical de cercanía y de servicio a los marginados y pobres de su época, en el "Pobrecito de Asis", en el "Padre de los pobres... que se conmueve al encontrar a alguien más pobre que él, y esto no por vanagloria sino por efecto de tierna compasión" (1Cel 76). Sin lugar a dudas, la pobreza como opción evangélica es el distintivo mayor de Francisco, que sin ser contestatario al modo de otros movimientos de su época se hace por su actitud, profeta de una sociedad justa y solidaria en donde se reconozca la dignidad de todo hombre.

Por otra parte, la fidelidad de Francisco a la Iglesia resulta evidente. En el contexto contestario de los movimientos pauperistas de la época, Francisco quiere ante todo permanecer fiel a la Santa Madre Iglesia (cf $1 \mathrm{R} X I X)$. Sin embargo, no cabe duda, que su fidelidad a la Iglesia estuvo muy lejos de ser una sumisión pasiva; al contrario su proyecto de vida eclesial resulta claramente creativo y original en un momento en que la Institución, paradojalmente llena de poder, amenaza ruina. Esta lectura de la realidad eclesial no es sólo de Francisco (cf L.May V) sino que coincide con aquella del mismo Papa Inocencio (cf $2 \mathrm{Cel} 17$ ), que al aprobar la Orden, aprueba de paso, el nacimiento de la Iglesia de los pobres bajo la inspiración de Francisco (cf Tes 18). Francisco no se deja seducir por la Iglesia del poder sino que opta por vivir según el evangelio al lado de los sin-poder, incluso permanenciendo él mismo como laico. Todo lo que signifique poder será relegado de la vida de los hermanos, ellos mismos llamados "menores" (1R VI, $3 ; \mathrm{VII}, 1-3)$. No se trata de crear una nueva iglesia o una iglesia dentro de la Iglesia, sino de mostrar el camino evangélico que todos en la Iglesia están llamados a vivir por el bautismo, de alli su interés por permanecer en la base, según le manifiesta al futuro Papa Honorio (2Cel 148).

La intención original de Francisco, que terminará con la aprobación canónica de una Orden Religiosa, es simplemente de vivir el seguimiento de Cristo, bajo el espíritu de la Bienaventuranzas, como una vocación propia de todo cristiano. La vida en penitencia que impulsa Francisco es el camino por el cual todo hombre y mujer, cualquiera sea su condición, puede llegar a la comunión escatológica con Dios (Cta T.F. 48). En este sentido, su fidelidad a la Santa Iglesia, que resulta de gran creatividad evangélica, tiene como objetivo llevar a la comunidad cristiana a vivir en fidelidad su vocación última de ser testimonio iconográfico de la comunión trinitaria y de la única voluntad económica de la Trinidad Santa.

Por ello, la Iglesia de los pobres que propicia Francisco, no busca la creación de una Iglesia paralela y contestataria, sino renovar al interior de la única Iglesia las relaciones de fraternidad y servicio como estructura fundamental de Comunión, que tiene como norma radical la contemplación del misterio de la Unidad en la Trinidad. Su proyecto reformador de la Iglesia pasa por la desclericalización de la liturgia, renovándole su carácter festivo y popular que permite a las grandes masas de iletrados hacer la experiencia vivificante de la 
presencia dinámica y liberadora de Dios. De igual modo, le devuelve a la comunidad cristiana su dimensión misionera -oscurecida, más bien, en aquella época por el espíritu de cruzada- como anuncio gozoso y fraternal del amor filantrópico de ese Dios que, siendo todo bien, se derrama por todo el universo. La Iglesia de los pobres que Francisco propicio recupera la dimensión espiritual/carismática de las comunidades -el Espíritu es para Francisco el verdadero Ministro de la Orden (2Cel 193)- superando el esquema juridico y jerárquico que poco o nada tiene que ver con la experiencia cristiana de Dios.

\section{E. Una Iglesia de Unidad en la Diversidad Y de Verdadera Comunión y Participación}

Si queremos que el laicado, según el querer del Concilio, participe en la vida de la Iglesia como verdadero protagonista y corresponsable de la misma, según se desprende de su común dignidad de discipulos de Cristo y de su membrecia a este pueblo sacerdotal, me parece que debemos superar algunos obstáculos presentes en la actual realización histórica del cristianismo católico occidental. En efecto, el gran pluralismo que reinó en la Iglesia primitiva choca en la actualidad con, al menos, dos aspectos de la organización eclesial: primero, la acción centralizadora del papado y la concepción de una Iglesia encargada de conservar la integridad doctrinal y disciplinar, en la que los ministros ordenados aparecen como simples reproductores y defensores de un paradigma eclesial y doctrinal que les viene desde arriba. En dicho esquema, los ministros encuentran muchas dificultades para dialogar. Se les prepara y se les envía a enseñar y guiar, resultándoles muy difícil aceptar que pueden aprender algo de los laicos o del mundo.

Segundo, la tentación de resolver el problema de la unidad en la diversidad por la "uniformización" sofocando con ello todos los intentos creativos y protagónicos de la base eclesial. Esto resulta contrario a la experiencia que se vivió, no sin dificultades, durante el primer milenio en base a la Pentarquía, es decir, a la comunión ecuménica de los cinco Patriarcados tradicionales con gran autonomía disciplinar, litúrgica, teológica, misionera, etc., pero capaces de mantener la comunión católica en base a los acuerdos de las grandes asambleas conciliares. Esto, que se mantiene aun vivo en oriente, puede indicar un camino cierto y original para la resolución de la tensión Unidad-Diversidad. No se trata de inventar algo novedoso sino reeditar una praxis probada durante varios siglos.

Tercero, debemos reconocer que el modelo eclesial que anima a muchos "clerigos" está marcado fuertemente por una vuelta a los tiempos previos al Vaticano II, especialmente por el olvido del la Eclesiologia del Pueblo de Dios, que significó "una verdadera revolución copernicana", pues dejaba atrás el viejo esquema de Sociedad Perfecta calcado de las monarquias de los siglos XVII y XVIII, para disponerse a estar en el mundo en una actitud de diálogo y servicio y a transparentar, por sus estructuras de comunión y participación, la esperanza escatológica de la Iglesia. En efecto, los textos del Vaticano II son citados sólo cuando sirven para justificar una práctica conveniente para la autoridad. Pareciera que la Iglesia de la comunión y participación, es releída y debe dejar 
paso a otra de "comunión" a secas, que en la práctica consagra la obediencia vertical a las autoridades como expresión de santidad y fidelidad.

Cuarto, aunque en la actualidad existen en diversas latitudes muchos signos de comunión y participación, resulta preocupante la formación que se está impartiendo en los seminarios a los futuros presbiteros, pues, se puede constatar que se está privilegiando una cierta identidad sacerdotal, de separación, por sobre una actitud de servicio, lo que refuerza fuertemente el clericalismo y aísla a los futuros ministros de la vida cotidiana de las comunidades y del mundo. No hay cercania ni interés por los pobres, por las mujeres, por los indígenas, por la política, etc., pareciera que sólo se forma para la conducción y adoctrinamiento de un rebaño dócil que debe someter su entendimiento y su obediencia a las «razones eclesiales" que se le imparten por la autoridad. Este esquema reproduce un modelo eclesial marcado por la uniformización y la no participación efectiva y protagónica de todo el Pueblo de Dios en la marcha de esta Iglesia peregrina.

Quinto, para una adecuada asunción de la tensión y el conflicto propios en las relaciones humanas, se hace fundamental experimentar un éxodo hacia nuevas formas, más evangélicas, tanto del ejercicio de la autoridad como de la obediencia en la Iglesia. Por un lado, la autoridad debe recuperar su dimensión de servicio que les es propia, pues toda autoridad en la Iglesia debe ejercerse en el estilo de Jesús, que, "siendo el Señor y el maestro", lavó los pies a sus discípulos y, por otro, la obediencia debe hacerse en la búsqueda común de la fidelidad al Proyecto de Dios en una corresponsabilidad efectiva. En efecto, la autoridad en la Iglesia debe romper los esquemas mundanos de la estructura de poder y de jerarquía al estilo de la estructura social de pecado actual ${ }^{20}$, para hacerse servidora de aquello que el Espíritu va suscitando en las comunidades, acogiendo con alegría los dones que él prodiga en los hermanos y recorriendo, junto con las comunidades, los nuevos senderos que nos va invitando a emprender. Por su parte, la obediencia para que sea humanizante no puede confundirse con el servilismo irreflexivo de los laicos. Si queremos laicos, hombres y mujeres, adultos y ponderadamente críticos, corresponsables en la vida de la Iglesia, es necesario crear instancias de real participación deliberativa y no sólo consultivas, pues la obediencia apunta al protagonismo activo y creativo y no sólo a la colaboración.

Finalmente, creo que en la medida que el nuevo modelo de la Iglesia como "Pueblo de Dios" se vaya haciendo realidad en un modelo concreto, como es el de las Comunidades Eclesiales de Base, el protagonismo corresponsable de los laicos estará asegurado. En efecto, las Comunidades Eclesiales de Base son un lugar óptimo para su desarrollo, pues en ellas se revive el modelo original de nuestra

20

Una práctica que R. MUÑOZ adelantaba hace algunos años, nos parece de una gran actualidad para el avance de estas nuevas maneras de vivir los ministerios en las comunidades: "los pastores deben estar insertos en sus comunidades, ojalá en una en concreto, para servirlas fraternalmente y desde dentro. En esas condiciones, las decisiones de los pastores han de ser fruto de un verdadero discernimiento comunitario, y de acuerdo con las orientaciones maduradas en procesos eclesiales más amplios, de participación abierta de las mismas comunidades y en comunión con los colegas en el ministerio" ("El pueblo y la comunidad. Testimonio y teologia desde la base", en: Pastoral popular 190 (1988) separata, p. 29). 
Iglesia como "red de comunidades hermanas unidas en la misma fe y en el mismo amor"; ellas son un factor primordial de promoción humana y desarrollo, un lugar donde el Espíritu prodiga la riqueza de sus carismas y ministerios, un espacio donde los bautizados viven la comunión y la participación y un foco de evangelización y de compromiso con el Reino de Dios. Es en ellas, que la Iglesia comienza a configurarse como una Iglesia toda ella ministerial superando el binomio "clérigos-laicos" con una mejor y original articulación en torno al binomio "comunidad-ministerios" y cuyo desarrollo tendrá alcances insospechados en el futuro próximo de la Iglesia. 